\title{
Towards a Circular Economy in the Aviation Sector Using Eco-Composites for Interior and Secondary Structures. Results and Recommendations from the EU/China Project ECO-COMPASS
}

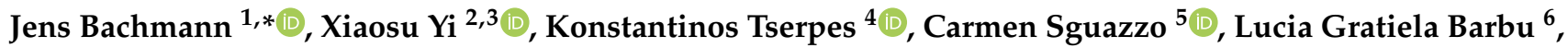 \\ Barbara Tse ${ }^{7}$, Constantinos Soutis ${ }^{7} \mathbb{D}$, Eric Ramón ${ }^{8}$, Hector Linuesa ${ }^{8}$ and Stéphane Bechtel ${ }^{9}$
}

Citation: Bachmann, J.; Yi, X.;

Tserpes, K.; Sguazzo, C.; Barbu, L.G.; Tse, B.; Soutis, C.; Ramón, E.; Linuesa, H.; Bechtel, S. Towards a Circular Economy in the Aviation Sector Using Eco-Composites for Interior and Secondary Structures. Results and Recommendations from the EU/China Project ECO-COMPASS Aerospace 2021, 8, 131. https:// doi.org/10.3390/aerospace8050131

Academic Editor: Giuliano Allegri

Received: 23 March 2021

Accepted: 23 April 2021

Published: 5 May 2021

Publisher's Note: MDPI stays neutral with regard to jurisdictional claims in published maps and institutional affiliations.

Copyright: (c) 2021 by the authors. Licensee MDPI, Basel, Switzerland. This article is an open access article distributed under the terms and conditions of the Creative Commons Attribution (CC BY) license (https:/ / creativecommons.org/licenses/by/ $4.0 /)$.
1 DLR-Deutsches Zentrum für Luft- und Raumfahrt e.V. (German Aerospace Center), Institute of Composite Structures and Adaptive Systems, 38108 Braunschweig, Germany

2 Faculty of Science \& Engineering, The University of Nottingham Ningbo China (UNNC), Ningbo 315100, China; xiaosu.yi@nottingham.edu.cn

3 AVIC Composite Corporation Ltd. (ACC), Beijing 100000, China

4 Laboratory of Technology \& Strength of Materials (LTSM), Department of Mechanical Engineering \& Aeronautics, University of Patras, 26500 Patras, Greece; kitserpes@upatras.gr

5 Laboratory of Optics and Experimental Mechanics (LOME), INEGI Institute of Science and Innovation in Mechanical and Industrial Engineering, 4200-465 Porto, Portugal; csguazzo@inegi.up.pt

6 CIMNE, Centre Internacional de Mètodes Numèrics a l'Enginyeria, C1, Campus Nord, Gran Capità, 08034 Barcelona, Spain; lgratiela@cimne.upc.edu

7 Department of Materials, University of Manchester, Oxford Road, Manchester M13 9PL, UK; barbara.tse@postgrad.manchester.ac.uk (B.T.); constantinos.soutis@manchester.ac.uk (C.S.)

8 Applied Chemistry \& Materials Department, Leitat Technological Center, C/de la Innovació 2, 08225 Terrassa, Spain; eramon@leitat.org (E.R.); hlinuesa@leitat.org (H.L.)

9 Airbus CRT (Central Research and Technology), Branch Located at Technocampus EMC ${ }^{2}$, 44340 Bouguenais, France; stephane.bechtel@airbus.com

* Correspondence: jens.bachmann@dlr.de

\begin{abstract}
Fiber reinforced polymers play a crucial role as enablers of lightweight and high performing structures to increase efficiency in aviation. However, the ever-increasing awareness for the environmental impacts has led to a growing interest in bio-based and recycled 'eco-composites' as substitutes for the conventional synthetic constituents. Recently, the international collaboration of Chinese and European partners in the ECO-COMPASS project provided an assessment of different eco-materials and technologies for their potential application in aircraft interior and secondary composite structures. This project summary reports the main findings of the ECO-COMPASS project and gives an outlook to the next steps necessary for introducing eco-composites as an alternative solution to fulfill the CLEAN SKY target.
\end{abstract}

Keywords: aviation; interior; secondary structure; eco-composite; bio-composite; natural fiber; bio-based; life cycle assessment; ECO-COMPASS; Europe; China; international collaboration

\section{Introduction}

This position paper was initiated as a result of the ECO-COMPASS EU/China collaboration project. The consortium was comprised of European and Chinese members of research centers, academia and aerospace industry, who cooperate in the development, characterization and modelling of eco-composites for the application in secondary structures and interior of civil airplanes.

The purpose of this project report is to provide an overview of the advantages and challenges of utilizing the so-called eco-composites made of bio-based and/or recycled constituents with the aim of substituting synthetic state-of-the-art materials used in aviation nowadays [1]. Additionally, multifunctional composites, typically electrically conductive 
carbon fiber reinforced composites are developed for function-integrated applications, in order to improve lightning strike protection of aviation structures. This shows that classic bio-based materials can be considered as "eco-composite", but this term may also be used for conventional materials, as long as their multifunctional performance during the use-phase is improved.

Note: As an emerging material, eco-composites mentioned in this project refers specifically to bio-based materials, recycled materials, and electrically conductive composites. It is certainly not a precise scientific definition and a standardization is necessary in order to ensure a common understanding.

This paper's objective is to inform and encourage decision makers within government and the aerospace industry to invest in the development and further assessment of ecocomposites for their best use in civil aerospace engineering. This is particularly as they can play a key role in the complex challenge to reduce the environmental impacts and non-renewable resource consumption of aviation and other transport sectors.

\section{Motivation}

Civil aviation is a success story, enabling safe, reliable and fast mobility in order to connecting people all over the world. As a consequence, considerable further growth of the civil aviation sector is predicted. Worldwide, an average annual increase of $3.7 \%$ of air traffic is forecasted for the next two decades, with Asia already on the pole position of flight numbers and by far the strongest growth expectations.

Note: How the COVID-19 pandemic impacts the forecasts cannot be foreseen in the current situation.

In contrast the aviation industry has to adapt further to the global need to decrease environmental impacts in a radical way. In 2016, the Paris Agreement was an important step showing the goodwill of the nations all over the world to combat climate change. However, few concrete actions have taken place so far. Global warming is the most prominent topic nowadays and aviation is the source of around $2 \%$ of world's greenhouse gas (GHG) emissions. In fact, aviation's GHG have a two or three times stronger effect when they are emitted at flight level compared to ground level, and takes much longer to be dispersed. Through the trend of decarbonization in other sectors, aviation is at risk of becoming a major source of GHG by 2050. A substantial rise is also forecasted for other aviation emissions such as $\mathrm{NO}_{\mathrm{x}}$, particulate matter, $\mathrm{SO}_{2}$ and water vapor. Delaying further action reduces any room for maneuver as the choices we make today will determine aviation in 2050.

The Advisory Council for Aviation Research and Innovation in Europe (ACARE) goals of Flightpath 2050 aim for a 75\% reduction in $\mathrm{CO}_{2}$ emissions per passenger kilometer and $90 \%$ reduction in $\mathrm{NO}_{x}$ emissions relative to a typical aircraft build in the year 2000 . Additionally, we live on a planet with limited resources, and hence, another important ACARE goal is a recyclable aircraft to reduce and finally avoid the consumption of nonrenewable materials. Recently, driven by the European Green Deal, the EU aims to be completely climate neutral by 2050 . It will be a powerful action, especially if it can be extended into a coordinated international undertaking. Transportation is one key sector facing a complex transition in improving our environmental footprint. In particular, in aviation, many meaningful solutions have to be developed and combined in an intelligent way to achieve these ambitious goals that cannot be fulfilled with a simple, single solution. In recent decades, a strong cooperation of EU aerospace manufacturing sector and $R \& D$ has already made considerable progress in the fuel efficiency of aircrafts. However, the increase in air traffic is more than compensates the positive effects. Further improvements are under development in all areas of aviation technology and EU projects like CleanSky2, SESAR and generally the Horizon 2020 framework are excellent examples for the positive effects of collaboration with the common goal to improve aviation efficiency. 
Disruptive measures, such as new aircraft configuration, alternative fuels, operational aspects, including the modernization and the improvement air traffic management technologies, flight procedures and systems are all parts of the puzzle. Not to forget materials and lightweight design to reduce the airplane weight, which is another crucial and much more fundamental factor in reducing energy consumption during the prolonged use-phase of airplanes. Already, composites made of carbon fibers and polymeric matrix systems play an important role as structural materials. Composites have many advantages when compared to metallic materials, such as superior specific mechanical properties, non-corrosiveness and improved fatigue performance. A further important advantage of composites is their ability to be tailored for different design requirements and integration of functions, enabling the manufacturing of more efficient aerodynamical configurations and built-in sensing for an early damage diagnosis.

Composites used nowadays in aviation are mainly made from non-renewable, fully synthetic constituents such as Polyacrylonitrile-based Carbon Fibers (CF). The energy intensive production process makes CF expensive, hindering a broader utilization in other industries, such as automotive and rail. Nevertheless, an annual growth of approximately $10 \%$ for the application of CFRP is forecasted in the next years. This leads to an everincreasing amount of production scrap and end-of-life waste. Due to their heterogenic structure and widespread use of crosslinked thermoset resin systems, the waste treatment of composite parts is very challenging. Today's state of the art allows only limited recycling, or better say downcycling, of CFRP parts. A real closed-loop recycling, i.e., one-to-one replacement of new materials with similar functionality, CF and other composite constituents is currently not economically feasible.

Generally, composites made from synthetic materials play a key role as enablers of lighter and more efficient structures in the civil aviation today and in the future. Considering the environmental challenge and related public concerns, the current considerations are changing, increasingly focusing on renewable and recycled materials. Historically, it might not be surprising, if one understands that the earliest aircraft structures were made from natural materials, such as wood. Today, almost entirely non-renewable materials with high energy consumption that are required for their production are used. However, not all structures in aviation demand the highest possible mechanical properties. Secondary structures and interior structures are candidates for the substitution of bio-based and recycled materials in order to reduce the consumption of non-renewables. Nevertheless, these "sustainable" materials still need to fulfil very demanding safety and performance requirements. In aviation, in particular, lightweight characteristic is one of the most crucial factors for any material to be considered a worthy candidate, as the use-phase has by far the highest influence on most environmental impact categories. To reduce the environmental impact of lightweight materials production, while still providing the necessary performance during use-phase, bio-based, recycled and multifunctional composites provide an ecological and economic solution [2-4].

\section{The ECO-COMPASS EU-China Project}

Starting in 2016, European and Chinese scientists and engineers were working in association in the ECO-COMPASS project to develop aeronautical composites with reduced environmental impact. The overall objective of the project was to provide a preliminary assessment on different types of eco-materials, including bio-based, recycled and multifunctional composites and their usability in aviation environment. This project report aims of providing a short summary of the main findings obtained in the ECO-COMPASS project, and in the following chapter, to provide further recommendations for upcoming research projects on how to improve the properties of eco-composites for application in aviation. The composites under investigation in ECO-COMPASS are made from naturally renewable resources, like plants and recycled carbon fibers with added functionality, where acoustic, vibration and electrical behavior can be tuned according to design needs (Figure 1). It was the objective of the joint effort to trial-manufacture secondary and interior 
structures for aircraft by using these newly developed material systems. The threshold for the introduction of new materials in aviation is comparatively high because of the challenging safety requirements, such as fire performance criteria for materials used in the cabin environment $[3,4]$.

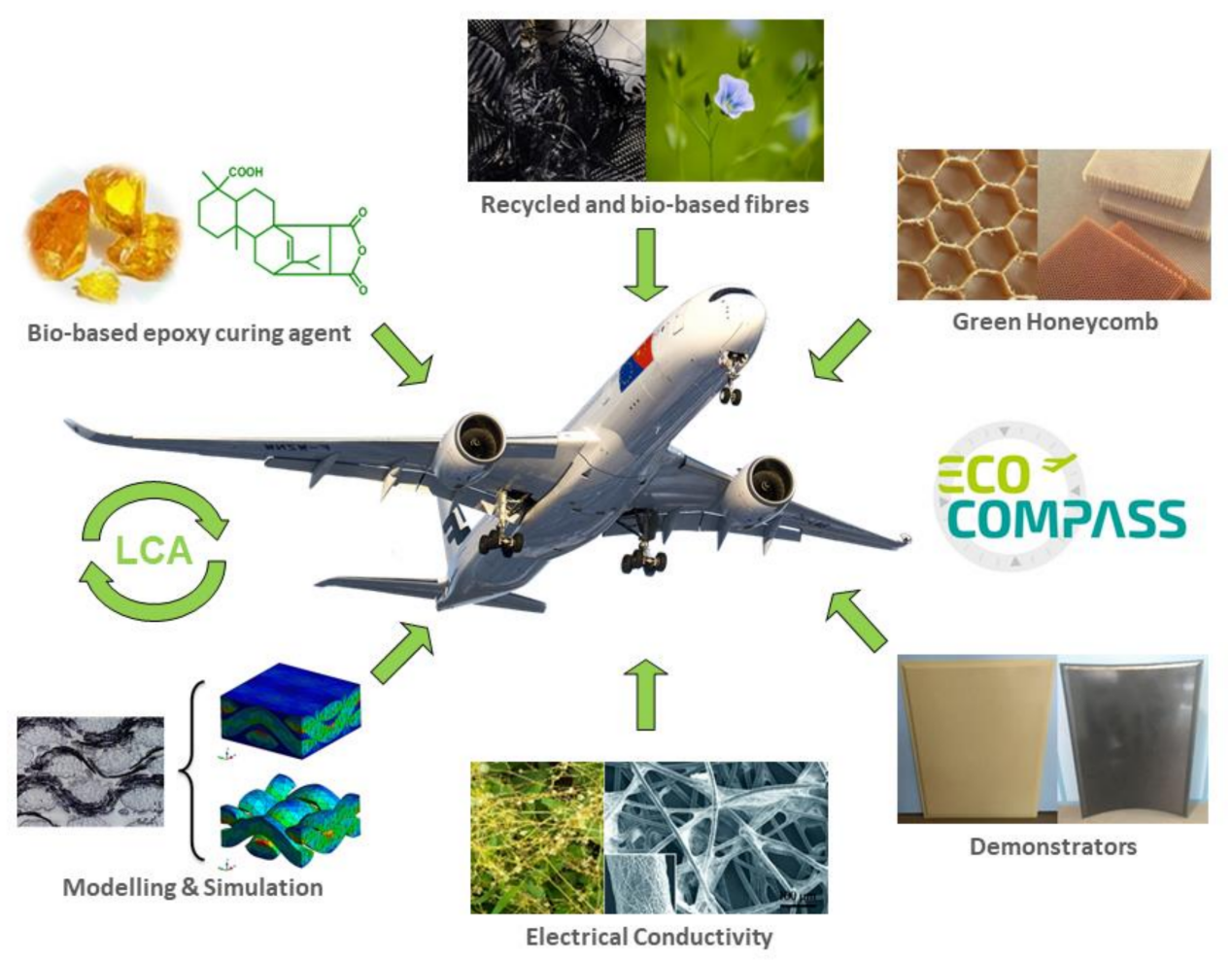

Figure 1. Examples of the materials and technologies developed during the ECO-COMPASS EU/China project.

Natural fibers, when used as reinforcing component of composites, are inexpensive, lightweight, and biodegradable and present unique mechanical, acoustic, and damping properties owing to their complex chemical and structural characteristics. However, the poor interfacial property between the hydrophilic plant fibers and the hydrophobic polymeric matrices results obviously in low mechanical properties. This becomes one of the major obstacles for their structural application, if the partial replacement of traditional glass fibers area used as reinforcement. A multi-scale shear lag model was proposed in the ECO-COMPASS project to take the full advantages of the hierarchical structure of the plant fiber reinforced composites. It is demonstrated that not only the fracture toughness, interfacial shear strength, tensile strength and modulus are improved by the component hybridization, nanoparticle grafting and nano-modification, but also the fire retardation and the anti-microbial performances. Moreover, the unique hollow structure of the plant fibers can provide additional benefit in structural damping, noise reduction and heat isolation compared to traditional glass or carbon fiber counterparts, behavior that is exactly desired for an aircraft interior structure [5-8]. Additionally, in the improvement of pure natural fiber reinforced polymer properties, the utilization of valuable recycled carbon fibers $(\mathrm{rCF})$ as alternatives to enhancing the properties of eco-composites has been considered. The down-cycled rCF usually retain most of their excellent mechanical properties, but are discontinuous and cannot simply replace long virgin carbon fibers. Therefore, wet-laid and carded hybrid nonwoven of flax and $\mathrm{rCF}$ were produced on a small laboratory scale. The positive effects on the flexural properties can be observed by adding even small amounts of $\mathrm{rCF}[9,10]$.

Natural fibers are used as one of the reinforcing materials in a composite, but can also be applied in their manufacturing process. For example, the conventional breather used in 
the vacuum forming process of composites is exclusively made of synthetic fibers. ECOCOMPASS project took the lead in developing the so-called green breather made partially of jute fibers. After testing by both Chinese and European partners, the green breather shows preliminarily a comparable, and even better process performance if compared with the synthetic fiber breathers. Moreover, a breather is a process consumable, which turns into industrial waste after one use. A green breather can be reused several times, and afterwards it can be used as filler material for composites. Finally, it can be thermally recycled while the synthetic fiber breather does not. Therefore, a green breather can obviously provide an alternative and a new possibility for upgrading the traditional breathers [11].

The utilization of natural fibers is generally very demanding regarding the fulfilment of fire regulations for interior structures in aviation. A combination of natural fibers and partly bio-based epoxy was the combination tested in ECO-COMPASS. As a result of the work carried out in the project, the addition of flame retardants on fiber and matrix level show very positive effects on flammability. However, heat release and smoke density requirements could not be fulfilled so far. In terms of flame retardancy, it is noteworthy that epoxy is apparently not as good as that of phenolic resin, and natural fiber is inherently flammable. To produce fire-retardant composites of flammable natural fiber and epoxy matrix in one step is obviously a very challenging task. One can either use a flame retardant to treat plant fibers, then impregnate it with phenolic resin, or the treat the bio-based resin flame retardant, and then impregnate carbon or glass fiber. Both steps should logically reduce the difficulty to produce fire retardant composites, which would meet the aeronautical requirements. ECO-COMPASS project has taken the first step in this direction $[3,12,13]$.

Besides fibers, bio-based polymers derived from natural resources are attracting attention for replacing traditional petrol-based plastics as a matrix in designing eco-friendly commodity bio-composites [14]. An overview of possible renewable resources based in a literature review is shown in Figure 2. For aviation, developing bio-based high-performance resins is a priority in substituting the traditional epoxies for use in structural applications. Rosin acid and itaconic acid have, thus, been synthesized, and formulated partly bio-based epoxy resins have been subsequently manufactured to produce eco-composites through genetic engineering technology. The bio-based content of the rosin acid and itaconic acid based curing agents under assessment in the ECO-COMPASS project was approximately $30-40 \%$. Both resin systems are still under development and an increased bio-based content of about $50 \%$ for the full resin systems are estimated to be achievable without compromise in resin performance. These matrix systems have resulted in equivalent, and in some cases, improved performance. Furthermore, intrinsically flame-retardant polymer matrix resins from renewable bio-resources are currently under development [15-17].

Further activities related to the bio-based resins have focused on the introduction of nanofillers into the epoxy matrix and the preparation of specimens for mechanical and fire retardant testing. Silicon carbide nanoparticles, carbon nanotubes and nano-clays have been selected as nanofillers to improve thermal, mechanical and conductive performance of the cured thermosets. Functionalized nanofillers have been dispersed in the epoxy matrix with an optimized method and result from tension and compression tests with neat resin and nano-modified samples show that the neat resins possess values comparable to the currently used epoxies in this field. Moreover, the addition of nanofillers leads to a significant increase in the electrical and mechanical properties of the neat resin. In any case, this promising technology needs to be further optimized and critically assessed for minimal ecological impact.

In addition to the reinforcing fibers and resin matrix, there is a third important component in the composite family, namely sandwich cores, such as honeycomb structures. The honeycombs used in the aviation industry are largely made of Nomex papers made of aramid fibers. ECO-COMPASS project has developed a so-called green honeycomb made partly of natural fibers and classic aramid fibers in a hybrid paper. After flame retardant treatment, the properties of the green honeycomb show comparable flammability behavior 
as that of traditional Nomex honeycombs. The process conditions for manufacturing are also very similar to that of the traditional one, but the raw material cost is slightly lower. This green honeycomb may become a new choice for future aviation sandwich composites [3].

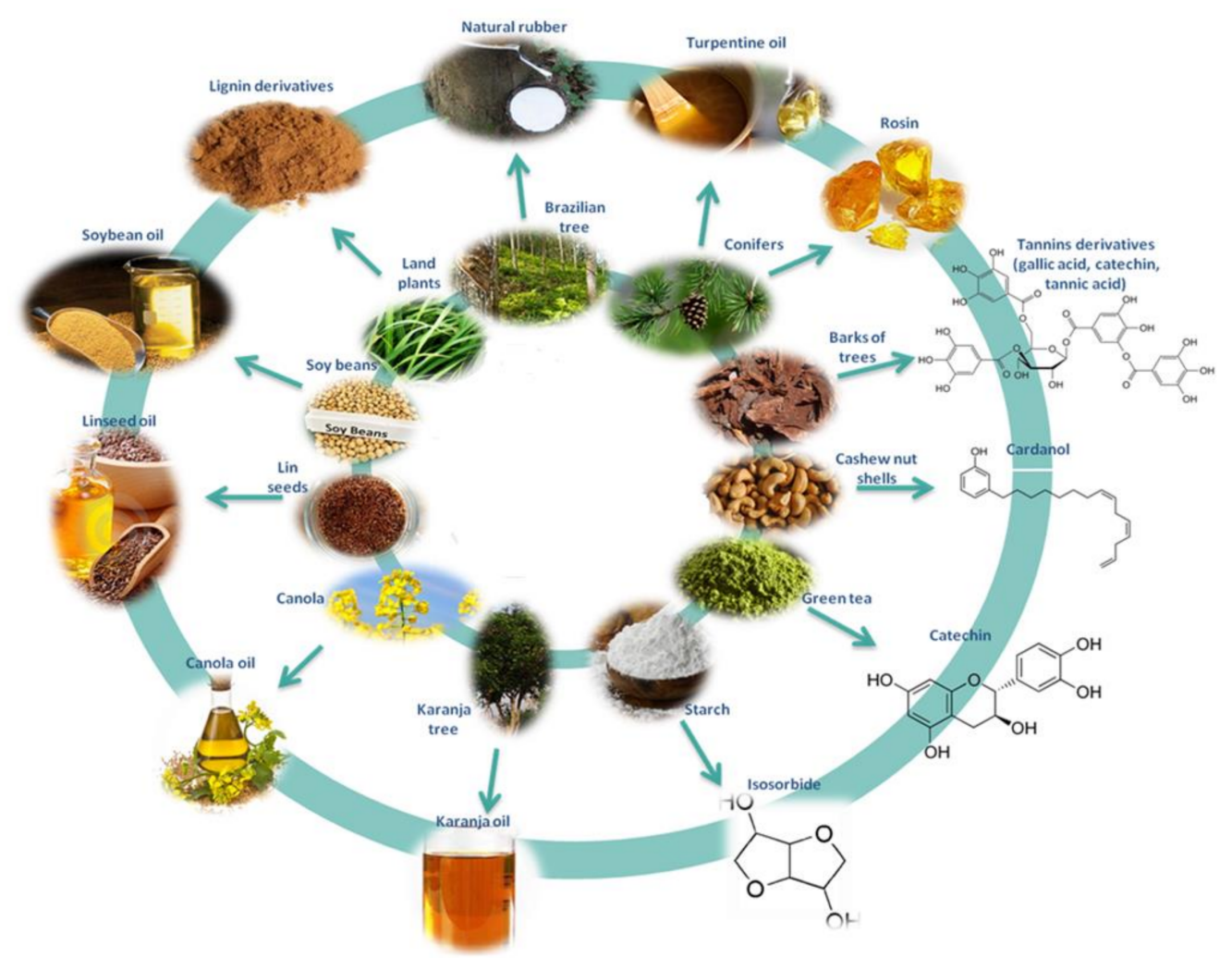

Figure 2. A selection of renewable resources for resin systems. Reprinted from ref. [14].

One viable strategy for enhancing the innovation level of eco-composites while addressing mass and volume constraints for the composite aircraft is the notion of material multifunctionality. Typically, the electrical conductivity of structural composites, in order to detect cracking, shield the electromagnetic interference and protect from a lightning strike. Accordingly, a Functionalized Interlayer Technology (FIT) was proposed that can simultaneously increase the electrical conductivity and the interlaminar fracture toughness. A coupled electrical-thermal-pyrolytic model was constructed and it shows that the lightning strike damage is strongly governed by the anisotropic electrical properties of the carbon fiber composite. A lightning damage criterion was proposed to evaluate the in-plane damage by temperature-dependent model and to estimate the in-depth damage by pyrolysis dependent model. Further investigations quantitatively elucidate the mechanism of the lightning strike on the composite laminates, supported by the experimental lightning strike test and propose solutions for increasing electrical conductivity of such material systems. The effort on Life Cycle Assessment of the multifunctional composites, in order to prove the ecological improvements compared to the standard CFRP, will be continued [18-27].

In order to facilitate the use of eco-composite materials in aeronautical structures, it is necessary to use numerical tools capable of accurately reproducing the performance of these materials, as in Figure 3. When these tools are applied to predict the mechanical response of the structure, they provide the displacements and reactions in the structure, as well as the strains and stresses in the different materials. All these results are used to evaluate the functionality and the integrity of the structure, in order to meet the required quality and safety standards. Also, based on the structure performance, the designer 
can define modification in its configuration in order to obtain an improved design. A first analysis of a generic hat-rack interior element made from eco-composites has been carried out in the ECO-COMPASS project. It has been demonstrated that the maximum deformations and the failure stress threshold are not exceeded, under service and ultimate loads respectively. The results obtained from the different simulations included proof that the software and numerical procedures developed in the framework of the ECO-COMPASS project are reliable tools for the optimal design of eco-composite aircraft structures. They are expected to facilitate, and encourage, the use of these new materials, in order to reduce the environmental footprint of civil aviation.
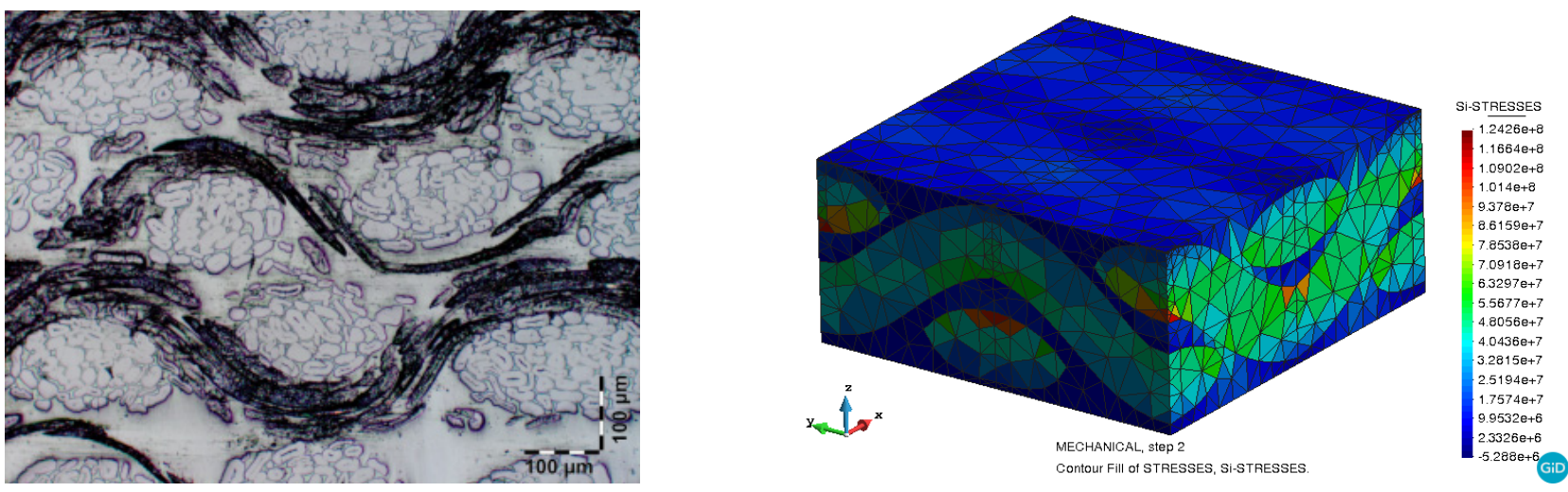

Figure 3. Microphotography of the ramie-woven skin and stresses obtained in the RVE model developed for its characterization when it is subjected to tensile loading.

Several interior and secondary structure demonstrators, such as an elevator panel and interior side-panel, show the potential of many eco-materials to be processed in a similar way compared to state-of-the-art composite materials. A preliminary Life Cycle Assessment carried out by the partners from China and Europe provides a first overview on environmental impacts of the ramie natural fiber and bio-based epoxy curing agent and compared to generic datasets of glass fibers respectively epoxy resin. A potential improvement in ecological impacts for bio-based materials is visible for impact categories such as global warming potential, mainly due to lower energy consumption. Furthermore, categories like Fossil Depletion Potential, Photochemical Oxidant Formation and Terrestrial Acidification show potential improvements. On the other hand, the cultivation of biobased materials can lead to higher emissions to water in the LCIA categories Freshwater Ecotoxicity and Eutrophication, a higher Ozone Depletion Potential and Human Toxicity. However, the results, so far, are based on many assumptions and simplifications by using laboratory data and generic data from commercial databases as substitutes for primary data on industrial level. [2,28].

In conclusion, the ECO-COMPASS project was a promising starting point to combine research activities on eco-composites in China and Europe. A broad range of different materials, technologies have been characterized, further developed and assessed. Now it is time to further reinforce the international collaboration to negate some challenges identified by the partners. Suggestions and recommendations are presented in the following section.

\section{Recommendations for the Successful Application of Eco-Composites in Aviation}

As described above, the eco-materials considered in the ECO-COMPASS project have a different maturity level for application in the demanding aviation environment. While materials, such as partly bio-based epoxy and hybrid honeycomb core already show very good performance, there are still many challenges to overcome for the successful introduction of eco-composites in meaningful amounts in the aviation sector. Therefore, our consortium from Europe and Chinese partners gives recommendations based on the 
findings from the ECO-COMPASS project, in order to further advance the properties and suitability of eco-composites for civil aviation applications.

So far, this work has focused on the substitution of state-of-the-art materials used in a similar conventional design as it is used nowadays in civil aviation. The next step must be to take into account more efficient designs for the future of aviation, like new aircraft configurations for hybrid or fully electric propulsion. The so-called disruptive designs and technologies will have different needs and requirements for materials than today's proven solutions. Generally, an assessment is recommended looking at the optimal distribution of high-performance materials and bio-based materials in less structurally demanding application areas, based on Life Cycle Engineering approach.

As mentioned in the preceding chapters, the so-called eco-composites in this position paper cover a wide range of different materials and technologies for their improvements. Included are also the classic synthetic high-performance composites, such as CFRP, which already have many advantageous characteristics compared to competing engineering materials. However, there is still a high potential for improving their usefulness by including functions while retaining their high structure efficiency. This may finally lead to a new lightweight strategy for airplane, namely "one material for multiple application". For example, by replacing a part of metallic conductors with high-conductivity modified composites for electrical structural network (ESN) to further reduce the overall material weight. The final choice of material should be based on a comprehensive assessment of competing materials with the aim of the lowest possible environmental impact over the whole life cycle.

\subsection{Life Cycle Assessment and Circular Economy}

For all material development on the background of reduction of environmental impacts, a holistic approach is needed, combining an optimal choice of materials, manufacturing and end-of-life treatment for any target application. The development should be accompanied from the earliest stage by a Life Cycle Assessment (LCA). Furthermore, Circular Economy principles should be followed in the choice of materials to identify optimal solutions to re-use or recycle any material at the end of life of an aviation structure. Of course, CE starts with the avoidance of materials as foremost aim. Extending a products life-time by damage detection and simple repairability is another important aspect of sustainability. Unavoidable EoL parts should be treated by a reasonable downcycling chain, in case that the products cannot be repaired or directly re-used for the same purpose. The conceptual "downcycling chain" (cascade) is standing for an LCA supported succession of suitable EoL treatments with as low as possible downgrading of the valuable material after each step. Generally, the recycled materials must have a lower environmental footprint compared to new materials they may substitute in a different application, otherwise the recycling makes no sense from ecological standpoint. Therefore, it is necessary not to only take into account a closed-loop recycling, but also an open-loop recycling in which the recycled materials are utilized in different applications.

As an example, today the pyrolysis route is the most matured method for the recycling of carbon fibers from CFRP waste. However, as the preceding step of size reduction to a length of usually much less than $100 \mathrm{~mm}$, the recycled carbon fibers $(\mathrm{rCF})$ are in fact downcycled to a product with lower value compared to virgin carbon fibers (vCF). A possible step to improve the value of such a material is to convert them into continuous forms of reinforcements, so that their good mechanical properties can be optimally exploited despite a limited fiber length. Delightfully after the conclusion of ECO-COMPASS, a follow-up research work on improved recovering of carbon fiber is in progress under more mild conditions in the GRACE project (Global Recycling And re-manufacturing of Composites for a circular Economy (GRACE). Bilateral Collaboration Project co-funded by National Natural Science Foundation of China (NSFC) and UKRI-EPSRC of United Kingdom, under Grand No. 5181101686, 2018). 
The suitability for successive recycling steps and their potential damage of the recycled material need to be characterized with the aim of finding the optimal recycling process parameters. A hybridization of natural fibers with $\mathrm{rCF}$ can be a way to find a suitable application for further downcycled materials, while improving the properties of natural fiber reinforced composites. Hybrid composites made of natural fibers and $\mathrm{rCF}$ have already been designed, manufactured and tested and preliminarily positive results have been obtained. Furthermore, more transparency is needed for the collection, disassembly and recycling chain, in order to identify the composite constituents, sort and streamline different waste streams for adapted recycling processes.

In order to improve the reliability and significance of the LCA results, we recommend investing more effort on primary data collection for different locations of raw material production, for example the natural fiber cultivation in Europe and China. This will support the improvement and optimization of fiber cultivation and extraction processes with the aim of reducing energy, water, land-use, fertilizer and pesticide consumption. For all LCA scenarios, the production mix of electricity is crucial for the energy intense processes. Hence, it is important to include realistic future scenarios for the mix of renewable and fossil energy in the different regions under consideration.

An interesting story about Circular Economy and sustainable development is the green breather developed in ECO-COMPASS. Green breather is partially made of jute fiber, and jute planting is just beneficial for improving soil quality and soil fertility. Therefore, the green breather project combines the agricultural production and improvement in natural fibers as a new type of industrial reinforcing material. This is exactly the social meaning of research and development of eco-composites, as it can integrate the entire ecological chain and the entire value chain.

For bio-composites, a special attention should be given to the LCA-based evaluation of potential protection technologies for bio-based composite materials that are developed to fulfill the challenging requirements of aviation. The environmental impacts of fiber modification technologies to improve mechanical properties of composites, like nanocellulose grafting, plasma treatments and classic chemical treatments assessed in the ECO-COMPASS project must be carefully modelled with realistic data.

Additionally, to the calculation of a state-of-the-art structure and a hypothetical replacement by eco-composites, the vision should be directed to the future designs of aviation. This includes a better utilization of the multifunctional aspects of bio-based materials, such as acoustic damping of natural fibers and the consequences on the weight reduction not just in the part using eco-composites itself but also in neighboring systems. Improved production methods with higher efficiency, local electricity mix for the production and transport distances between the manufacturing locations must be considered. Attention should be given furthermore for harmonization between software tools and methods, for example by adapting principles of the Product Environmental Footprint (PEF) introduced by the European Commission. Finally, the data transparency initiative for LCA improves the acquisition of reliable data, and as a result, the comparability of technologies with regard to our common sustainability objectives. It is also proposed to establish a public LCA database of ecologically improved aviation materials by joint efforts of Chinese and European partners.

\subsection{Eco-Materials}

Eco-composite materials, studied so far within ECO-COMPASS, include basically two components, namely bio-based epoxy resins, and natural fibers for reinforcing polymer matrix composites, and for hybrid papers for honeycomb, respectively. By taking the existing aeronautical composites as a benchmark, it is obvious that there is still a gap between the eco-composite and the state-of-the-art one. Therefore, all basic eco-composite components should be further improved in properties to achieve better performance and to fulfil the state-of-the-art requirements. Additionally, the relationship between composition-property-process condition of the new composites is obviously not well- 
understood yet. The multi-scale and multi-level structure of the hierarchical composite system should be further studied and used for performance improvements. There were many attempts performed in ECO-COMPASS, such as chemical modification, including nano-modification. However, an effective and affordable way could be simply found in the hybridization of the eco-compositions with conventional material compositions, in order to match their potential. In ECO-COMPASS project, such investigations were performed and the results show, on average, improvements in the flame retardant, damping or conductivity properties. Consequently, the study should be continued.

On the other hand, only few research activities have tackled the fatigue and ageing behavior of eco-composites, especially the challenges for composites containing natural fibers. Safety is of utmost importance when introducing new materials into aviation. Therefore, more effort needs to be invested in the field of ageing resistance, with a focus on characterization, understanding and innovative improvements of eco-composites behavior during the use-phase of many years under severe conditions. Examples are moisture uptake of natural fibers, temperature differences and ultraviolet radiation. A possible influence of bio-based specific challenges needs to clarified regarding the update of certification procedures.

The combination of natural fibers and epoxy resin is very demanding regarding the fulfilment of fire regulations for interior structures in aviation. For the combination of natural fibers and epoxy resin, an improvement in heat release is needed without sacrificing smoke density and toxicity. Further tests are proposed in order to increase the understanding of the positive and negative effects of flame retardants. Generally, the combination of natural fibers with less fire sensitive resin systems, like furfuryl alcoholbased variants, made to a high percentage from renewable resources like sugarcane bagasse, is recommended. Similarly, the combination of E or S glass fibers with bio-based resin systems can be another way to a first introduction of partially bio-based eco-composites in aviation. In short, a complex composite system can be broken down into individual material components, which can be then tackled one by one in a possibly simple and affordable approach.

Looking at the thermoset systems as matrix for composites, some promising alternatives within different groups of bio-based epoxy systems are of interest within the research. Such thermoset systems are explored with the primary aim of obtaining renewable alternatives to petroleum based polymeric materials. Nevertheless, often it is not possible to establish a direct connection between the material science and chemistry research to specific engineering field of applications, including the aeronautic sector. Within the ECO-COMPASS project, a literature review of bio-based thermoset resin systems as composite matrix was carried out, highlighting some potentialities for interiors and secondary structures of airplanes. The main mechanical properties, such as tensile, flexural, impact resistance of the bio-based resin systems compare favorably with those of currently used petroleum-based counterparts, but further analysis is required. Systems belonging to isosorbide-, furan- and rosin-based systems, and in a minor measure, to natural-oil-based systems, showed feasible characteristics in application as matrix for secondary and interior structure composite.

It is proposed that within each class of resin systems, a holistic approach to the investigation is adopted. This would start with a new chemical formulation and the scalingup of the new resin systems and continues with the assessment of key properties related to the compatibility with matrix fibers and the validation of the physical properties of the final fiber composites as whole. The processability protocols from laboratory environment to the industrial production level constitute the concluding stage. Further functionalization of bio-based matrix systems by nano-filler inclusion needs to be investigated with the aim of improving fire resistance, electrical and ageing properties. This highlights that, despite advances in the use of bio-based epoxy systems and multi-functional nanocomposites, there is still a need to further optimize their performances to make them feasible for industrial production and competitive for applications in the aviation sector. Generally, alongside 
with the engineering research in new formulations of multifunctional eco-composites, research has to be carried out with the aim of building nano-functionalized materials safer by design. An assessment of best practices in nano-safety must be addressed during the scale-up from the laboratory to industrial level. Further studies must be conducted in the multi-functionalization steps of new resin systems before meeting the commercial production level, in order to guarantee the sustainability of the proposed new materials and related manufacturing processes and applications.

LCA studies are necessary to assess and improve the entire lifespan of new ecocomposite products during the different life-stages.

\subsection{Modelling and Simulation}

Modelling and understanding the specific material behavior should be done from a Life Cycle Engineering (LCE) approach, taking into account environmental, economic and technical aspects. Adapting design principles is recommended in order to take advantage of the specific properties of eco-materials, such as material damping and acoustic behavior coming from the intrinsic characteristics of natural fibers.

It should be emphasized that the structural modelling carried out by ECO-COMPASS was mainly aimed at the coupon level. In fact, the scope of composite modelling is more ambitious, such as multi-composition, multi-scale and multi-level structural design and modelling, designing multifunctionality into micro- and meso-composite structures, and modelling and simulation of the performance of eco-composite structures at engineering scale under airplane service condition. Therefore, extensive and in-depth research in this direction is needed in the future.

Modelling and simulation can lead to a significant reduction in the development time and cost of bio-composites. Simulation-aided design and optimization of bio-composites may benefit from existing models that have been developed for classical CFRPs. Mechanical, thermal and electrical properties of bio-composites can be predicted using both analytical and numerical models. In ECO-COMPASS, FE-based multi-scale models have been developed to predict the electrical and thermal properties of two bio-composites, namely a carbon fiber/rosin and a carbon fiber-flax/epoxy and a nanofilled bio-resin (MWCNT/epoxy). The numerical predictions correlate very well with corresponding experimental measurements. Using the models, the effects of geometrical and materialrelated parameters on the thermal and electrical conductivities have been studied. From the parametric study, rough guidelines for the production process have been developed. The overall performance of the models confirms that they can be used in future investigations aimed at designing, implementing and validating bio-composites in aircraft interior and secondary structural parts.

The mechanical behavior of bio-composites has been studied at a specimen level using numerical homogenization techniques, such as multi-scale analysis, which made the modelling of complex microstructures possible. The results have shown good agreement with the experimental work performed in the consortium. These techniques have been then used in the numerical study of a hat-rack. An optimization analysis has been conducted to determine the fiber orientation best suited to obtain optimal structural behavior. This shows the potential of this type of analysis to aid in the design practice and further the introduction of bio-composites in the aeronautical field. However, its applicability should be further investigated on other types of components to demonstrate its reliability.

One of the main challenges is to accurately characterize the mechanical behavior of natural fiber composites, which might be the case for other types of composites, but these material systems show a bigger scatter. It is harder to control and avoid imperfections and defects. Therefore, the models developed for their structural analysis need to account for this variability in material properties. To address this problem, it is necessary to develop formulations that couple the material model with stochastic (statistical) procedures, based on multilevel Monte Carlo formulations. This poses new constrains in the material model, as it has to provide a good material characterization, and must also 
have a reduced computational cost. With these requirements, the serial-parallel mixing theory is the perfect candidate. This theory obtains, by means of compatibility equations, the composite performance from the response of its constituent materials. The stochastic material models developed will be used to conduct a robust optimization of bio-composite laminate structures. This sort of optimization procedures perform a stochastic analysis of each design and the function to be minimized is the mean value of the structural response, as well as its variance. Using this approach, it is possible to obtain an optimal solution for the structure accounting for the uncertainties that might be over it. Furthermore, it is well-known that long term effects, such as fatigue loads have an important role in the material mechanical failure and further research should be conducted in this direction to establish the behavior of bio-composites under cyclic loading.

\subsection{International Collaboration}

In order to fulfil the goals of a meaningful lowered environmental impact of aviation, the benefits of international collaborations should be further followed to gather force for a more effective development and application of eco-composites as one part of the solution. Such an alignment of research activities has a high potential to increase the speed of invention and to bring synergies to the surface. For example, there are different types of natural fibers available in every region of our world. Some, like flax and ramie, have promising properties and can be utilized as "local" materials for composites. On the other hand, the cultivation of some plants, such as jute can improve the soil so that both agricultural progress and the supply of industrial raw materials can be taken into account. Such a win-win example of combining industry and agriculture can be implemented in different regions of the world by international cooperation.

\section{Conclusions}

Composites made of carbon fibers and petrol-based matrix systems play a crucial role as enablers of lightweight and high performing structures to increase the efficiency of aviation. However, the ever-increasing awareness for the environmental impacts leads to a growing interest in bio-based and recycled 'eco-composites' as substitutes for the conventional synthetic composite constituents. Recently, the international collaboration of Chinese and European partners in the ECO-COMPASS project provided an assessment of different eco-materials and technologies for their potential application in aircraft interior and secondary composite structures. Although preliminary, the present research has highlighted materials-enabled potential, and an alternative part of the solution to the CLEAN SKY target. Obviously, the work needs to be continued, in order to optimize the properties of these material systems and understand the fundamental issues that affect their performance. A case study from the ECO-COMPASS project has demonstrated the successful combination of partly bio-based epoxy resin combined with conventional carbon fibers for the manufacturing of an empennage side panel, including lightning strike protection, as in Figure 4. Another example is the green honeycomb-based sandwich side panel for airplane interior. Further details on technical aspects, discussed in this White Paper, can be found in journal articles published by the consortium during this international collaboration [2-27] and public deliverables on the project website.

It will be decisive for the successful implementation of bio-based and recycled materials in the aviation composite structures, in order to fully understand and exploit their potential and use them in an optimal way. The technical improvements should be supported by a holistic Life Cycle Assessment (LCA) to identify challenges in the form of environmental impacts compared with conventional materials. A careful examination of the different environmental impacts has to be carried out in order to avoid any shift of burden from global warming potential towards other impact categories, e.g., the eutrophication potential. The LCA should accompany the material and technology development from the earliest stage for a Life Cycle Engineering (LCE) approach towards a Circular Economy. 
Based on many assumptions and simplifications, the LCA results from the ECOCOMPASS project show a major impact of the use-phase for all environmental impact categories, resulting from the kerosene consumption for usually more than 25 years of aircraft usage. In comparison to the use-phase, materials, production, assembly and endof-life treatments have a less impact. Nevertheless, it should be the aim of the aviation industry to fulfill the ambitious targets to be climate neutral by 2050 in conjunction with a Circular Economy that leads to a sustainable utilization of materials with a minimized environmental effect. Bio-based and recycled materials are important factors with a great potential to be a part of the puzzle.

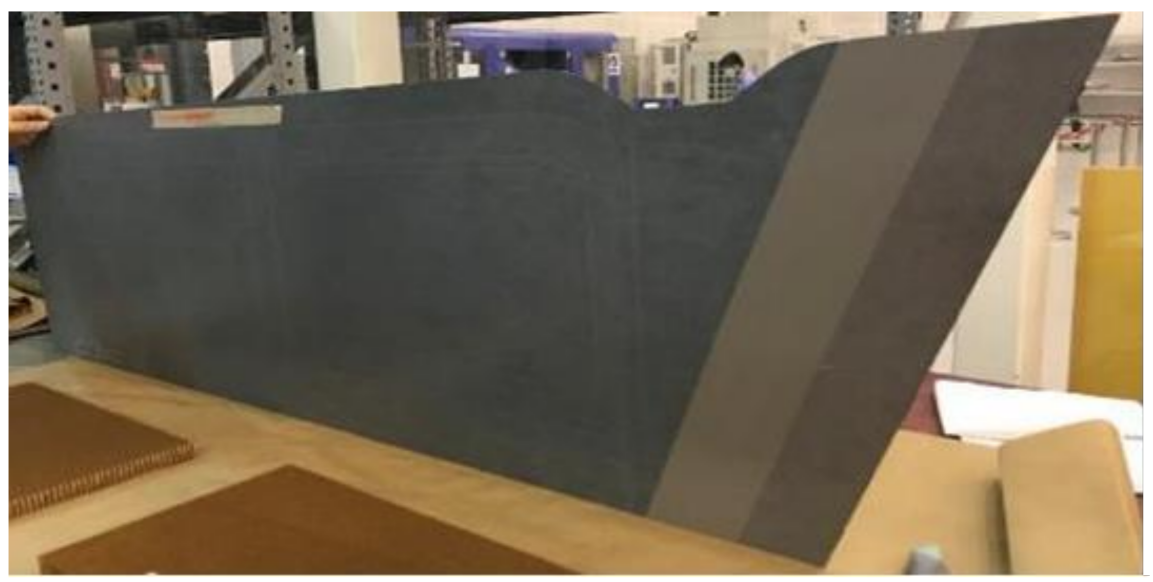

Figure 4. Demonstrator trailing edge panel of a horizontal tail, an example for the combination of conventional materials like carbon fibers with partly bio-based epoxy resin developed during the ECO-COMPASS project.

On the technical side, one needs to further work in concert on the improvement of challenging aspects of such materials, which are for examples moisture ingress, fire ignition and propagation, creep and ageing properties, by the help of innovative technologies suitable for different types of natural fibers and resin systems. On the other hand, the positive aspects of bio-based materials, for example low density, noise reduction and vibration damping of natural fibers, need to be fully exploited for the best performance of eco-composites. An international collaboration project reviewing the development of ecocomposites for civil aviation is an effective way in improving bio-based materials available all over the world. Additionally, it should be emphasized that affordability is another key factor in aerospace and other industries, and thus, additional effort is devoted to low cost and more effective manufacturing methods, in addition to analysis and computational simulation of the manufacturing and assembly process.

So far, mainly conventional state-of-the-art structures have been considered to study the implementation of eco-materials. To take the next step, we recommend working closely together with designers of future aircraft with the aim of finding the optimal combination of conventional, bio-based and recycled materials. Hybrid solutions, such as a mixture of natural fibers with new or recycled carbon fibers, could be one viable way forward. Generally, the emergence of bio-based, recycled and multifunctional eco-composites offer a unique opportunity for materials and aircrafts that can provide an alternative way for aeronautical structures, and expand state-of-the-art technologies.

Author Contributions: Conceptualization and methodology, J.B., K.T. and X.Y.; investigation, J.B., X.Y., K.T., Carmen Squazzo, L.G.B., B.T., C.S. (Constantinos Soutis), E.R., H.L.; writing-original draft preparation, J.B., X.Y.; writing-review and editing, J.B., X.Y., K.T., C.S. (Carmen Sguazzo), L.G.B., B.T., C.S. (Constantinos Soutis), E.R., H.L., S.B.; visualization, J.B.; supervision, K.T., C.S. (Constantinos Soutis); project administration and funding acquisition, J.B., X.Y. All authors have read and agreed to the published version of the manuscript. 
Funding: This project has received funding from the European Union's Horizon 2020 research and innovation programme under grant agreement No 690638 and the Ministry for Industry and Information of the People's Republic of China under grant agreement No [2016]92.

Institutional Review Board Statement: Not applicable.

Informed Consent Statement: Not applicable.

Data Availability Statement: The list of references gives an overview of the publications related to the ECO-COMPASS project. A list of public deliverables and conference presentations describing the technical work carried out in the project in more detail can be found at the project website www.eco-compass.eu.

Acknowledgments: We want to thank all partners that worked on Chinese and European side of the ECO-COMPASS project for their valuable contribution to the success of the ECO-COMPASS project.

Conflicts of Interest: The authors declare no conflict of interest.

\section{References}

1. Soutis, C. Introduction: Engineering requirements for aerospace composite materials. In Polymer Composites in the Aerospace Industry; Irving, P.E., Soutis, C., Eds.; Elsevier, Woodhead Publishing: Cambridge, UK, 2015; pp. 1-17. ISBN 978-0-85709-523-7.

2. Bachmann, J.; Hidalgo, C.; Bricout, S. Environmental analysis of innovative sustainable composites with potential use in aviation sector-A life cycle assessment review. Sci. China Technol. Sci. 2017, 60, 1301-1317. [CrossRef]

3. Yi, X.; Tong, J.; Zhang, X.; Zhu, J.; Liu, X.; Xian, G.; Li, Y.; Ding, F.; Rudd, C.; Khalili, P. Bio-Polymers and Bio-Composites. In Revolutionizing Aircraft Materials and Processes; Pantelakis, S., Tserpes, K., Eds.; Springer: Cham, Switzerland, 2020.

4. Bachmann, J.; Yi, X.; Gong, H.; Martinez, X.; Bugeda, G.; Oller, S.; Tserpes, K.; Ramon, E.; Paris, C.; Moreira, P.; et al. Outlook on ecologically improved composites for aviation interior and secondary structures. CEAS Aeronaut. J. 2018, 9, 533-543. [CrossRef]

5. Zhang, J.; Shen, Y.; Jiang, B.; Li, Y. Sound Absorption Characterization of Natural Materials and Sandwich Structure Composites. Aerospace 2018, 5, 75. [CrossRef]

6. Li, Q.; Li, Y.; Zhou, L. A micromechanical model of interfacial debonding and elementary fiber pull-out for sisal fiber-reinforced composites. Compos. Sci. Technol. 2017, 153, 84-94. [CrossRef]

7. Wang, C.; Ren, Z.; Li, S.; Yi, X. Effect of Ramie Fabric Chemical Treatments on the Physical Properties of Thermoset Polylactic Acid (PLA) Composites. Aerospace 2018, 5, 93. [CrossRef]

8. Li, Y.; Yi, X.; Yu, T.; Xian, G. An overview of structural-functional-integrated composites based on the hierarchical microstructures of plant fibers. Adv. Compos. Hybrid Mater. 2018, 1, 231-246. [CrossRef]

9. Tse, B.; Yu, X.; Gong, H.; Soutis, C. Flexural Properties of Wet-Laid Hybrid Nonwoven Recycled Carbon and Flax Fibre Composites in Poly-Lactic Acid Matrix. Aerospace 2018, 5, 120. [CrossRef]

10. Bachmann, J.; Wiedemann, M.; Wierach, P. Flexural Mechanical Properties of Hybrid Epoxy Composites Reinforced with Nonwoven Made of Flax Fibres and Recycled Carbon Fibres. Aerospace 2018, 5, 107. [CrossRef]

11. Yi, X.; Zhang, X.; Tong, J.; Li, Y.; Xian, G. Development of Bio-Composites for Green Aviation and Ground Vehicles (Feature). SAMPE J. 2018, 54, 16-26.

12. Khalili, P.; Liu, X.; Yeow Tshai, K.; Rudd, C.; Yi, X.; Kong, I. Development of fire retardancy of natural fiber composite encouraged by a synergy between zinc borate and ammonium polyphosphate. Compos. Part B 2018, 159, 165-172. [CrossRef]

13. Khalili, P.; Liu, X.; Yeow Tshai, K.; Kong, I.; Rudd, C.; Yi, X. The effects of microcrystalline cellulose on the flammability and thermal behaviours of flame retarded natural fibre epoxy composite. World J. Eng. 2019. [CrossRef]

14. Ramon, E.; Sguazzo, C.; Moreira, P. A Review of Recent Research on Bio-Based Epoxy Systems for Engineering Applications and Potentialities in the Aviation Sector. Aerospace 2018, 5, 110. [CrossRef]

15. Dai, J.; Peng, Y.; Teng, N.; Liu, Y.; Liu, C.; Shen, X.; Mahmud, S.; Zhu, J.; Liu, X. High-Performing and Fire-Resistant Biobased Epoxy Resin from Renewable Sources. ACS Sustain. Chem. Eng. 2018, 6, 7589-7599. [CrossRef]

16. Zhang, X.; Wu, Y.; Wei, J.; Tong, J.; Yi, X. Curing kinetics and mechanical properties of bio-based composite using rosin-sourced anhydrides as curing agent for hot-melt prepreg. Sci. China Technol. Sci. 2017, 60, 1318-1331. [CrossRef]

17. Yi, X.; Zhang, X.; Ding, F.; Tong, J. Development of Bio-Sourced Epoxies for Bio-Composites. Aerospace 2018, 5, 65. [CrossRef]

18. Tserpes, K.; Kora, C. A Multi-Scale Modeling Approach for Simulating Crack Sensing in Polymer Fibrous Composites Using Electrically Conductive Carbon Nanotube Networks. Part II: Meso- and Macro-Scale Analyses. Aerospace 2018, 5, 106. [CrossRef]

19. Dong, Q.; Guo, Y.; Chen, J.; Yao, X.; Yi, X.; Ping, L.; Jia, Y. Influencing factor analysis based on electrical-thermal-pyrolytic simulation of carbon fiber composites lightning damage. Compos. Struct. 2016, 140, 1-10. [CrossRef]

20. Guo, Y.L.; Dong, Q.; Chen, J.L.; Yao, X.; Yi, X.; Jia, Y. Comparison between temperature and pyrolysis dependent models to evaluate the lightning strike damage of carbon fiber composite laminates. Compos. Part A Appl. Sci. Manuf. 2017, 97, 10-18. [CrossRef]

21. Yi, X.; Guo, M. Functionalized Interlayer Technology to make Structural Composites Highly Toughened and Simultaneously Electrically Conductive (Feature). SAMPE J. 2018, 54, 6-14. 
22. Zhao, Z.; Zhang, B.; Du, Y.; Hei, Y.; Yi, X.; Shi, F.; Xian, G. MWCNT modified structure-conductive composite and its electromagnetic shielding behavior. Compos. Part $B$ 2017, 130, 21-27. [CrossRef]

23. Guo, Y.; Xu, Y.; Wang, Q.; Dong, Q.; Yi, X.; Jia, Y. Enhanced lightning strike protection of carbon fiber composites using expanded foils with anisotropic electrical conductivity. Compos. Part A 2018, 117, 211-218. [CrossRef]

24. Dong, Q.; Wan, G.; Guo, Y.; Yi, X.; Jia, Y. Coupled thermal-mechanical damage model of laminated carbon fiber/resin composite subjected to lightning strike. Compos. Struct. 2018, 206, 185-193. [CrossRef]

25. Guo, M.; Yi, X. Preparation of highly electrically conductive carbon-fiber composites with high interlaminar fracture toughness by using silver-plated interleaves. Compos. Sci. Technol. 2019, 176, 29-36. [CrossRef]

26. Wan, G.; Dong, Q.; Zhi, J.; Guo, Y.; Yi, X.; Jia, Y. Analysis on electrical and thermal conduction of carbon fiber composites under lightning based on electrical-thermal-chemical coupling and arc heating models. Compos. Struct. 2019, 229. [CrossRef]

27. Tserpes, K.; Tzatzadakis, V.; Bachmann, J. Electrical Conductivity and Electromagnetic Shielding Effectiveness of Bio-Composites. J. Compos. Sci. 2020, 4, 28. [CrossRef]

28. Dong, S.; Xian, G.; Yi, X. Life Cycle Assessment of Ramie Fiber Used for FRPs. Aerospace 2018, 5, 81. [CrossRef] 